\title{
Association of CYP3A polymorphisms with the pharmacokinetics of cyclosporine $A$ in early post- renal transplant recipients in China
}

Xiang-guang $\mathrm{MENG}^{1}$, Cheng-xian GUO ${ }^{1}$, Guo-qing FENG ${ }^{2}$, Ying-chun ZHAO ${ }^{3}$, Bo-ting ZHOU ${ }^{1,4}$, Jian-le $\mathrm{HAN}^{5}$, Xin $\mathrm{CHEN}^{5}$, Yong $\mathrm{SHI}^{5}$, Hong-yao SHI ${ }^{5}$, Ji-ye YIN ${ }^{1}$, Xiang-dong PENG ${ }^{1}$, Qi PEI ${ }^{1}$, Wei ZHANG ${ }^{1}$, Guo WANG ${ }^{1}$, Meng $\mathrm{HE}^{6}$, Min LIU ${ }^{6}$, Jing-ke YANG ${ }^{7}$, Hong-hao ZHOU ${ }^{1, *}$

\begin{abstract}
${ }^{1}$ Institute of Clinical Pharmacology, Hunan Key Laboratory of Pharmacogenetics, Central South University, Changsha 410078, China; ${ }^{2}$ Department of Pharmacology, School of Medicine, Zhengzhou University, Zhengzhou 450001, China; ${ }^{3}$ Osteoporosis Research Center, Creighton University, Omaha, Nebraska 68131, USA; ${ }^{4}$ Department of Pharmacy, Xiangya Hospital, Central South University, Changsha 410008, China; ${ }^{5}$ Department of Organ Transplantation, Zhengzhou № 7 People's Hospital, Zhengzhou 450016, China; ${ }^{6}$ Department of Pharmacy, Zhengzhou Central Hospital Affiliated to Zhengzhou University, Zhengzhou 450007, China; ${ }^{7}$ Department of Hematology,
\end{abstract} Henan Cancer Hospital, Zhengzhou 450003, China

Aim: To evaluate retrospectively the association of cytochrome P450 3A (CYP3A) and ATP-binding cassette sub-family B member 1 (ABCB1) gene polymorphisms with the pharmacokinetics of cyclosporine $A(C s A)$ in Chinese renal transplant patients.

Methods: One hundred and twenty-six renal transplant patients were recruited. Blood samples were collected, and corresponding clinical indices were recorded on the seventh day after the procedure. The patients were genotyped for CYP3A4*1G, CYP3A5*3C, ABCB1 $1236 \mathrm{C}>\mathrm{T}, \mathrm{ABCB} 12677 \mathrm{G}>\mathrm{T} / \mathrm{A}$, and ABCB1 $3435 \mathrm{C}>\mathrm{T}$ polymorphisms. Whole blood trough concentrations of CsA at time zero $\left(\mathrm{C}_{0}\right)$ were measured before the drug administration. A multiple regression model was developed to analyze the effects of genetic factors on the CsA dose-adjusted $C_{0}\left(C_{0} /\right.$ dose $)$ based on several clinical indices.

Results: The CYP3A5*3C polymorphism influenced the $C_{0}$ and $C_{0} /$ dose of CsA, which were significantly higher in patients with the GG genotype than in patients with the AA or GA genotypes. No significant differences were detected for other SNPs (CYP3A4*1G, ABCB1 1236 C > T, ABCB1 2677 G>T/A, and ABCB1 3435 C > T). In a univariate analysis using Pearson's correlation test, age, hemoglobin, blood urea nitrogen and blood creatinine levels were significantly correlated with the log-transformed CsA $C_{0} /$ dose. In the multiple regression model, CYP3A5*3C, age, hemoglobin and blood creatinine level were associated with the log-transformed CsA $C_{0} /$ dose. Conclusion: CYP3A5*3C correlates with the $C_{0}$ /dose of CsA on the seventh day after renal transplantation. The allele is a putative indicator for the optimal CsA dosage in the early phase of renal transplantation in the Chinese population.

Keywords: cyclosporine A; pharmacokinetics; CYP3A; ABCB1; gene polymorphism; pharmacogenetics; renal transplantation

Acta Pharmacologica Sinica (2012) 33: 1563-1570; doi: 10.1038/aps.2012.136; published online 22 Oct 2012

\section{Introduction}

Cyclosporine A (CsA) is a calcineurin inhibitor (CNI) that is efficient but costly in the clinic. Since 1978, it has been widely used to reduce delayed graft function (DGF) and the acute rejection (AR) response of patients receiving a renal transplant $\{\text { Colombo, } 2011 \# 4\}^{[1]}$. Because of the narrow therapeutic window and large inter-individual variations in pharmacokinetics, therapeutic drugs are monitored in kidney transplant recipients to achieve target therapeutic trough blood levels ${ }^{[2]}$.

\footnotetext{
* To whom correspondence should be addressed.

E-mail hhzhou2003@163.com

Received 2012-07-15 Accepted 2012-08-21
}

Currently, the blood trough concentration at zero $\left(\mathrm{C}_{0}\right)$ is considered to be influenced by several clinical factors, including age, the hemoglobin level, and the blood creatinine $(\mathrm{BCr})$ level ${ }^{[3]}$. However, variations in CsA pharmacokinetics are poorly explained by non-genetic factors. Therefore, genetic factors, particularly the cytochrome P450 3A (CYP3A) and ATP-binding cassette sub-family B member 1 (ABCB1) gene activity in the intestine and liver, could help predict CsA pharmacokinetics in early post-renal transplant recipients.

CYP3A, which participates in CsA metabolism, is primarily composed of CYP3A4 and CYP3A5 in adults ${ }^{[4]}$. Numerous CYP3A single nucleotide polymorphisms (SNPs) have been identified to date, and these can be obtained from several SNP 
databases, such as dbSNP (http://www.ncbi.nlm.nih.gov/ snp/) and HapMap (http:/ / www.hapmap.org). Some CYP3A polymorphisms have been shown to correlate with CsA pharmacokinetics. For example, CYP3A5*3C, a splicing mutation in intron 3, results in an mRNA splice defect with a premature stop codon, yielding truncated and non-functional proteins ${ }^{[5]}$. Several studies have reported that the CYP3A5*3C/*3C genotype correlates with a higher $\mathrm{CsA}_{\mathrm{C}_{0}} /$ dose in early renal transplant patients ${ }^{[6,7]}$, whereas other studies have demonstrated that the variant locus has no effect on the $C_{0} /$ dose $^{[8,9]}$. Moreover, several studies on the high-frequency CYP3A4*1G allele in intron 10 revealed that the CYP3A4*1G/ ${ }^{*} 1 \mathrm{G}$ genotype affects drug metabolism in healthy subjects, suggesting that CYP3A4*1G could affect CYP3A4 activity in vivo ${ }^{[10,11]}$. Other independent research groups did not observe a correlation between CYP3A4*1G and CsA pharmacokinetics in patients on the seventh day after renal transplantation or in early bone marrow transplant patients ${ }^{[7,12]}$. However, a linkage disequilibrium (LD) has been observed between CYP3A4*1G and CYP3A5 ${ }^{*} 3 \mathrm{C}$ in Asian populations. Namely, CYP3A5*1 allele carriers display a greater probability of harboring the CYP3A4 ${ }^{*} 1 \mathrm{G}$ allele than the CYP3A4* 1 allele $^{[13]}$. Taken together, these data highlight the importance of thoroughly validating the association between CYP3A polymorphisms and CsA pharmacokinetics.

ABCB1, which encodes the drug transporter P-glycoprotein, plays an important role in pumping out exogenous substances (eg, CsA) from cells ${ }^{[14]}$. Numerous SNPs in ABCB1 have also been reported and can be obtained from the above-mentioned databases. To date, researchers have primarily focused on the associations between three polymorphisms $(1236 \mathrm{C}>\mathrm{T}$ in exon $12,2677 \mathrm{G}>\mathrm{T} / \mathrm{A}$ in exon 21, and $3435 \mathrm{C}>\mathrm{T}$ in exon 26) and CsA pharmacokinetics, but the results have been inconsistent. Several studies have suggested that the non-synonymous variant $2677 \mathrm{G}>\mathrm{T} / \mathrm{A}$ and synonymous variant $3435 \mathrm{C}>\mathrm{T}$ might contribute to the differences in CsA pharmacokinetics ${ }^{[6,7]}$, whereas others reported that neither polymorphism affected the CsA $C_{0}{ }^{[15,16]}$. Furthermore, the three SNPs were in LD with one another. Additional studies have demonstrated that the TTT, CGC, and TGC haplotypes correlate significantly more with the CsA $\mathrm{C}_{0}$ than with other ABCB1 1236-2677-3435 haplotypes ${ }^{[7,17]}$.

Apart from genetic factors, clinical indices, which are likely to yield confounding effects, may affect the inter-individual variability of CNI pharmacokinetics ${ }^{[18]}$ and consequently lead to a reduction in or a complete blockade of genetic effects. Therefore, a combined analytical method (eg, regression model) may be advantageous for investigating the associations between genetic factors and CsA pharmacokinetics. A combined analytical method is commonly used to study differences in CsA pharmacokinetics in non-Chinese renal transplant patients, but it is rarely applied in studies involving Chinese patients. Therefore, we validated the effects of the CYP3A4, CYP3A5, and ABCB1 genetic polymorphisms on CsA pharmacokinetics in early renal transplant patients by establishing a regression model.
In this study, we first examined the effects of CYP3A and $\mathrm{ABCB} 1$ polymorphisms on the CsA $C_{0}$ and $C_{0} /$ dose in early renal transplant recipients. Next, we analyzed the impact of their haplotypes on CsA pharmacokinetics. Finally, we established a multiple linear regression model to further evaluate the contribution of polymorphism to CsA pharmacokinetics based on clinical indices.

\section{Materials and methods Patients}

One hundred and twenty-six subjects were recruited from 634 Chinese patients who underwent de novo renal transplantation in Zhengzhou № 7 People's Hospital between May 2003 and July 2008. All demographic and clinical data were obtained from hospital records. All recipients accepted a triple immunosuppressive therapy regimen containing CsA (Neoral ${ }^{\circledR}$; Novartis Pharma, Eberbach, Germany), mycophenolate mofetil (CellCept ${ }^{\circledast}$; Roche, Shanghai, China), and a corticosteroid. A standard steroid regimen of $500 \mathrm{mg}$ of methylprednisolone was given intravenously at the time of surgery and for each of the next two days, daily. On the third day after the procedure, oral prednisolone was administered at $100 \mathrm{mg}$ and then progressively decreased to a daily dose of $20 \mathrm{mg}$ by the end of the first month. Patients who met the following criteria were included in the study: (1) Han Chinese; (2) between 18 and 60 years of age; (3) an ABO blood type compatibility; (4) human leukocyte antigen matching to no less than two loci; (5) negative for panel reactive antibody; and (6) complementdependent cytotoxicity less than $10 \%$. Patients who had a history of renal transplantation or multiple organ transplantation; were taking other medications that influence CsA; had a history of hepatitis B, hepatitis C, or HIV; or could not procure medical records were excluded from the study.

\section{Determination of the CsA $C_{0}$ and $C_{0} /$ dose}

The starting CsA dosage, which was initiated on the second day after the operation, was $4-6 \mathrm{mg} / \mathrm{kg}$ per day. Then, according to the CsA $C_{0}$, the daily dosage was adjusted to a full blood concentration of $200 \mathrm{ng} / \mathrm{mL}$. Clinical indices, such as age, body weight, urinary volume, and full blood concentrations of hemoglobin, blood urea nitrogen $(\mathrm{BUN})$, and $\mathrm{BCr}$, were recorded on the seventh day after transplantation. CsA was administered in equal amounts at 8:00 $\mathrm{AM}$ and 8:00 PM daily. Blood samples were collected with ethylenediaminetetraacetic acid as the anticoagulant at 8:00 AM before drug administration. The CsA $C_{0}$ was determined using an Architect $^{\circledR}$ i1000 analyzer (Abbott Laboratories, Abbott Park, IL, USA). The $C_{0} /$ dose $\left(\mathrm{ng} / \mathrm{mL}\right.$ per $\left.\mathrm{mg} \cdot \mathrm{kg}^{-1} \cdot \mathrm{d}^{-1}\right)$ was calculated using the following equation:

$$
C_{0} / \text { dose }=C_{0}(\mathrm{ng} / \mathrm{mL}) / \text { Dose }\left(\mathrm{mg} \cdot \mathrm{kg}^{-1} \cdot \mathrm{d}^{-1}\right)
$$

The initial $C_{0}$ was selected in this study based on its important role in rapidly attaining a target concentration for renal transplant patients compared with concentrations tested at other time points. The $C_{0} /$ dose was chosen for analysis based on its consistency in patients. The study protocol was approved by the Ethics Committee of the Xiangya School of Medicine, Cen- 
tral South University. Written informed consent was provided by all participants before the study began. We also obtained clinical permission from the Chinese Clinical Trial Register (Registration № ChiCTR-ONC-12002181) for this work.

\section{Genotyping}

Genomic DNA was isolated from peripheral blood leukocytes using an SQ Blood DNA Kit (Omega, CO, USA) according to the manufacturer's protocol. CYP3A4*1G was genotyped using a polymerase chain reaction (PCR)-restriction fragment length polymorphism assay, whereas CYP3A5*3C and ABCB1 $3435 \mathrm{C}>\mathrm{T}$ were genotyped by pyrosequencing, and ABCB1 $1236 \mathrm{C}>\mathrm{T}$ and ABCB1 $2677 \mathrm{G}>\mathrm{T} / \mathrm{A}$ were genotyped by direct sequencing. The primer sequences used are listed in Table 1. The following PCR conditions were employed: $94^{\circ} \mathrm{C}$ for $7 \mathrm{~min}$ followed by 35 cycles of $94^{\circ} \mathrm{C}$ for $30 \mathrm{~s}$ and $62^{\circ} \mathrm{C}$ for $60 \mathrm{~s}$ for CYP3A $4^{*} 1 \mathrm{G}$ and $95^{\circ} \mathrm{C}$ for $5 \mathrm{~min}$ followed by 35 cycles of $95^{\circ} \mathrm{C}$ for $30 \mathrm{~s}$ and $50^{\circ} \mathrm{C}$ for $30 \mathrm{~s}$ for CYP3A5*3C, ABCB1 $1236 \mathrm{C}>\mathrm{T}$, ABCB1 2677 G>T/A, and ABCB1 3435 C >T. PCR analysis was performed with an Eppendorf thermal cycler (Eppendorf AG, Hamburg, Germany), whereas pyrosequencing was performed using the Pyrosequencer 96MA (Biotage, Uppsala, Sweden). As a quality control, $5 \%$ of the samples were re-genotyped by direct sequencing.

\section{Statistical analysis}

SHEsis Online (http://analysis.bio-x.cn; access date: 2012-01-12) was used to calculate the frequencies of the CYP3A4, CYP3A5, and ABCB1 polymorphisms and their pairwise LDs. The haplotype analysis for CYP3A4-CYP3A5 and ABCB1 1236-2677-3435 was performed using PHASE 2.1 (downloaded from http:/ / stephenslab.uchicago.edu/software.html; access date: 2012-01-02). Deviations from HardyWeinberg expectations were calculated using $\chi^{2}$ analysis. The clinical characteristics of the renal transplant recipients were expressed as the mean \pm standard deviation, median (range).
The Shapiro-Wilk test was used to assess the normal distribution of the data from CsA pharmacokinetics. Data exhibiting an abnormal distribution were expressed as the median (range) and analyzed by non-parametric tests (eg, the Nemenyi test for comparing three groups and the Mann-Whitney $U$ test for comparing two groups). The $C_{0}$ / dose was log-transformed to attain normality. To select clinical candidate predictors for fitting a multiple regression model, we individually examined each one against the log-transformed $C_{0} /$ dose using Pearson's correlation test. The variables associated with the log-transformed $C_{0}$ /dose were retained $(P<0.05)$ and further analyzed with the multiple regression model by the stepwise method. The dummy variables were used as category variables in the stepwise regression model.

All statistical analyses were performed using SPSS 16.0 (SPSS, Chicago, IL, USA). For each analysis, $P<0.05$ was considered statistically significant.

\section{Results}

\section{Patient characteristics and polymorphism distribution}

As shown in Table 2, the mean age of the 126 renal transplant recipients was $37.0 \pm 10.1$ years; their mean body weight was $61.9 \pm 10.0 \mathrm{~kg}$; and the ratio of male to female participants was 93:33. Table 3 lists the allele and genotype frequencies of CYP3A and ABCB1. The expected frequencies for all SNPs did not differ from the Hardy-Weinberg principle $(P>0.05)$. As many studies have reported that an LD exists between CYP3A4*1G and CYP3A5*3C, and among ABCB1 1236, ABCB1 2677, and ABCB1 3435, we investigated these polymorphisms in our samples. CYP3A4*1G and CYP3A5*3C were in $\mathrm{LD}\left(D^{\prime}=0.638\right)$, as were ABCB1 1236, ABCB1 2677, and ABCB1 3435 ( $D^{\prime}=0.781,0.831$, and 0.554 , respectively). We performed corresponding analyses according to the CYP3A4CYP3A5 and ABCB1 1236-2677-3435 haplotypes and eventually obtained 4 and 11 haplotypes, respectively. Among the CYP3A4-CYP3A5 haplotypes, the main GG and AA haplotype

Table 1. Genotyping of CYP3A4, CYP3A5, and ABCB1 using the PCR-restriction fragment length polymorphism, pyrosequencing, and direct sequencing assays.

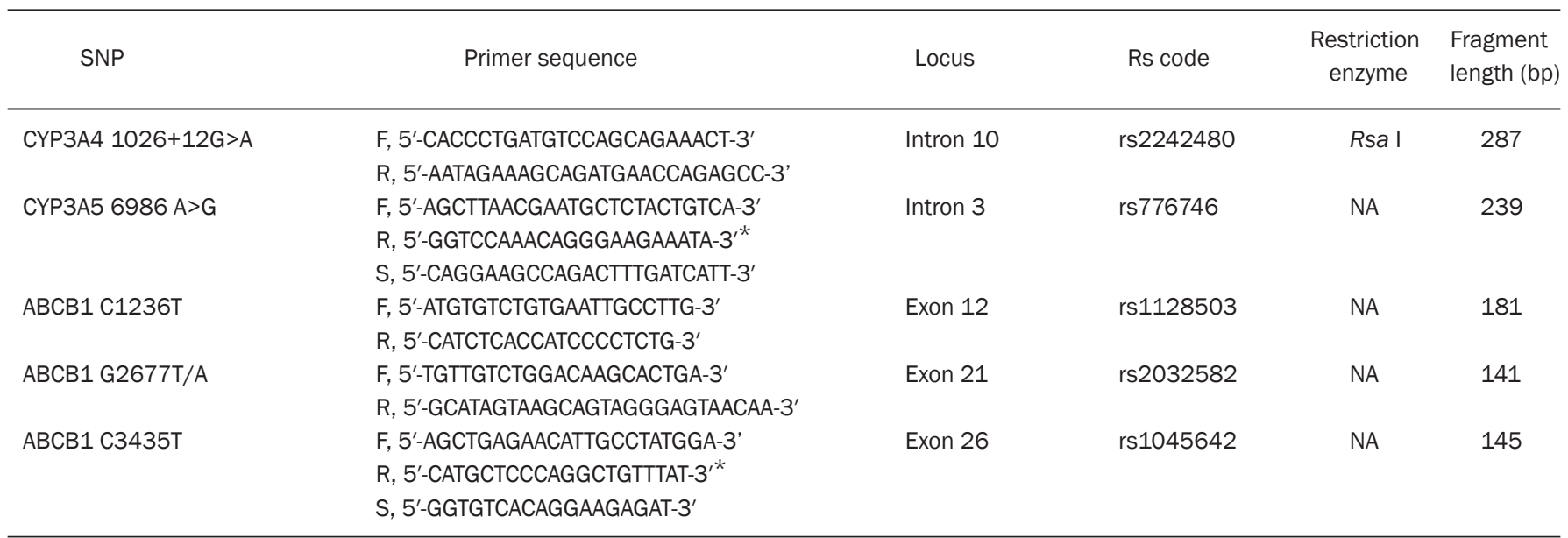

NA indicates not applicable. * Labeled by biotin. 
Table 2. Patient characteristics.

\begin{tabular}{|c|c|c|}
\hline Characteristic & $n$ & $\begin{array}{c}\text { Value/frequency } \\
\text { (Mean } \pm \text { SD, Median, Range) }\end{array}$ \\
\hline Age (years) & 126 & $37.0 \pm 10.1,36(18-60)$ \\
\hline \multicolumn{3}{|l|}{ Gender } \\
\hline Male & 93 & $73.8 \%$ \\
\hline Female & 33 & $26.2 \%$ \\
\hline Body weight (kg) & 126 & $61.9 \pm 10.0,61.0(40.0-91.0)$ \\
\hline \multicolumn{3}{|l|}{ Native kidney disease } \\
\hline Hypertension & 44 & $34.9 \%$ \\
\hline Chronic & 33 & $26.2 \%$ \\
\hline \multicolumn{3}{|l|}{ Glomerulonephritis } \\
\hline Diabetes mellitus & 20 & $15.9 \%$ \\
\hline Other & 11 & $8.7 \%$ \\
\hline Nephrotic syndrome & 7 & $5.6 \%$ \\
\hline IgA nephropathy & 5 & $4 \%$ \\
\hline Polycystic kidney disease & 3 & $2.4 \%$ \\
\hline Chronic pyelonephritis & 2 & $1.6 \%$ \\
\hline Latent glomerulonephritis & 1 & $0.8 \%$ \\
\hline \multicolumn{3}{|l|}{ Donor } \\
\hline Living related donor & 109 & $86.5 \%$ \\
\hline Deceased donor & 17 & $13.5 \%$ \\
\hline Cold ischemia time $(\mathrm{h})$ & 126 & $7.1 \pm 3.2,8.0(0.2-15.0)$ \\
\hline CsA daily dose $(\mathrm{mg} / \mathrm{d})$ & 126 & $302.2 \pm 49.4,300.0(200.0-450.0)$ \\
\hline $\mathrm{CsA} C_{0}(\mathrm{ng} / \mathrm{mL})$ & 126 & $209.5 \pm 98.8,194.9$ (33.8-547.6) \\
\hline$C_{0} /$ dose $(\mathrm{ng} / \mathrm{mL}$ per $\mathrm{mg} / \mathrm{kg})$ & 126 & $42.9 \pm 20.4,39.1(6.8-18.3)$ \\
\hline Urinary volume (L) & 126 & $\begin{array}{l}3342.8 \pm 1326.9,3240.0 \\
(1200.0-8000.0)\end{array}$ \\
\hline Hemoglobin $(\mathrm{g} / \mathrm{L})$ & 126 & $92.9 \pm 13.3,92.0(61.0-132.0)$ \\
\hline BUN (mmol/L) & 126 & $12.7 \pm 7.8,10.7(4.3-56.7)$ \\
\hline $\mathrm{BCr}(\mu \mathrm{mol} / \mathrm{L})$ & 126 & $190.7 \pm 219.6,127.1(54.9-1640.2)$ \\
\hline
\end{tabular}

frequencies were $62.4 \%$ and $19.6 \%$, respectively. Among the ABCB1 1236-2677-3435 haplotypes, the frequencies of the main TTT, TGC, and CGC haplotypes were $34.4 \%, 24.3 \%$, and $17.2 \%$, respectively.

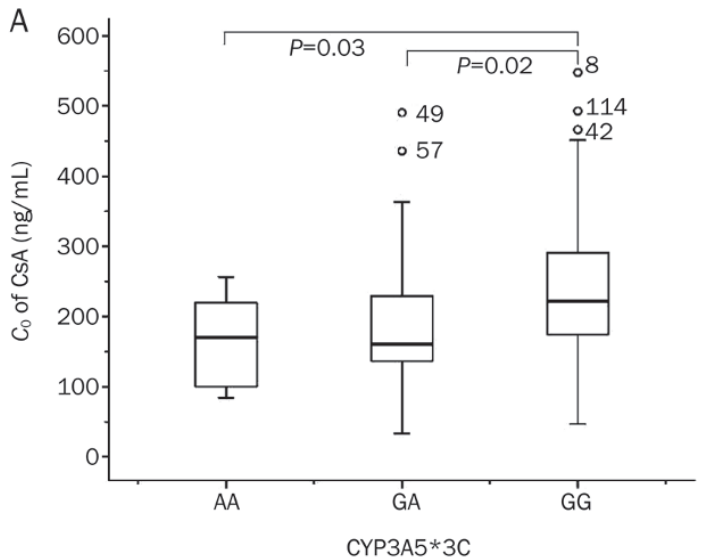

Table 3. Genotyping of CYP3A and ABCB1.

\begin{tabular}{|c|c|c|c|c|}
\hline \multirow{2}{*}{$\begin{array}{c}\text { SNP } \\
\text { ABCB1 C1236T }\end{array}$} & \multicolumn{2}{|c|}{$\begin{array}{l}\text { Allele frequency } \\
\qquad(n, \%)\end{array}$} & \multicolumn{2}{|c|}{$\begin{array}{l}\text { Genotype frequency } \\
(n, \%)\end{array}$} \\
\hline & C & $87(34.5)$ & $\mathrm{CC}$ & $19(15.1)$ \\
\hline & $\mathrm{T}$ & $165(65.5)$ & CT & 49 (38.9) \\
\hline & & & $\mathrm{TT}$ & $58(46)$ \\
\hline \multirow[t]{6}{*}{ ABCB1 G2677T/A } & G & $109(43.3)$ & GG & $26(20.6)$ \\
\hline & $\mathrm{T}$ & $107(42.5)$ & GT & 39 (31) \\
\hline & $A$ & $36(14.3)$ & GA & $18(14.3)$ \\
\hline & & & $\mathrm{TT}$ & $29(23)$ \\
\hline & & & $\mathrm{AA}$ & $4(3.2)$ \\
\hline & & & $\mathrm{TA}$ & $10(7.9)$ \\
\hline \multirow[t]{3}{*}{ ABCB1 C3435T } & C & $154(61.1)$ & $\mathrm{CC}$ & $51(40.5)$ \\
\hline & $\mathrm{T}$ & $98(38.9)$ & CT & $52(41.3)$ \\
\hline & & & $\mathrm{TT}$ & $23(18.3)$ \\
\hline \multirow[t]{3}{*}{ CYP3A4*1G } & G & $186(73.8)$ & GG & $72(57.1)$ \\
\hline & $A$ & $66(26.2)$ & GA & $42(33.3)$ \\
\hline & & & $\mathrm{AA}$ & $12(9.5)$ \\
\hline \multirow[t]{3}{*}{ СYР $3 A 5 * 3 C$} & A & $78(31)$ & $\mathrm{AA}$ & $16(12.7)$ \\
\hline & G & $174(69)$ & $A G$ & $46(36.5)$ \\
\hline & & & GG & $64(50.8)$ \\
\hline
\end{tabular}

Impact of genetic factors on CsA pharmacokinetics

We examined CYP3A4, CYP3A5, and ABCB1 polymorphism associations with the $\mathrm{CsA} C_{0}$ and $C_{0}$ /dose. All results are shown in Figure 1 and Table 4 . The CYP3A5*3C polymorphism exhibited significant differences between the $A G$ and GG genotypes, and between AA and GG $(P<0.05)$, in the $C_{0}$ and $C_{0}$ /dose groups. No significant differences were detected for other SNPs (CYP3A4*1G, ABCB1 1236 C>T, ABCB1 2677 $\mathrm{G}>\mathrm{T} / \mathrm{A}$, and ABCB1 $3435 \mathrm{C}>\mathrm{T}$ ). We selected GG and AA

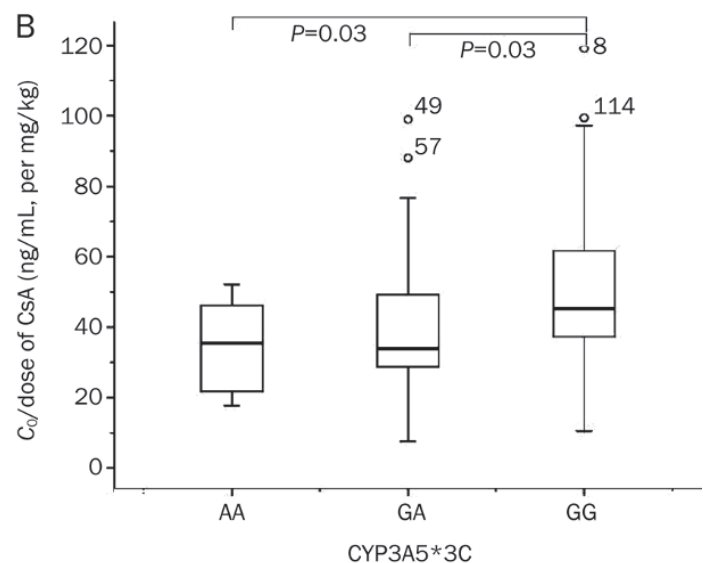

Figure 1. Differences in the $\operatorname{CsA}(A) C_{0}$ and $(B) C_{0}$ /dose among CYP3A5*3C genotypes on the seventh day after renal transplantation in the study group $(n=126)$. 
Table 4. Associations between the CYP3A and ABCB1 polymorphisms and CsA pharmacokinetics.

\begin{tabular}{ccc}
\hline & $\operatorname{CsA~}_{0}(\mathrm{ng} / \mathrm{mL})$ & $\mathrm{C}_{0} /$ dose \\
Number & Median (Range) & $(\mathrm{ng} / \mathrm{mL}$, per mg/kg) \\
& & Median (Range)
\end{tabular}

\begin{tabular}{llll}
\hline ABCB1 1236 C>T & & & \\
CC & 19 & $183.6(71.5-363.2)$ & $38.0(14.3-75.7)$ \\
CT & 49 & $200.9(33.8-435.9)$ & $41.5(6.8-87.2)$ \\
TT & 58 & $194.9(47.1-547.6)$ & $39.1(9.7-118.3)$
\end{tabular}

ABCB1 2677 G>T/A

$\begin{array}{llll}\text { GG } & 26 & 176.8(52.6-390.3) & 36.7(11.0-79.5) \\ \text { GT/GA } & 57 & 203.5(33.8-547.6) & 41.5(6.8-118.3) \\ \text { TT/AA/TA } & 43 & 194.5(82.2-490.4) & 39.2(17.5-98.1) \\ \text { ABCB1 3435 C>T } & & & \\ \text { CC } & 51 & 177.8(33.8-451.3) & 37.0(6.8-93.0) \\ \text { CT } & 52 & 208.4(47.1-547.6) & 42.7(9.7-118.3) \\ \text { TT } & 23 & 201.2(82.2-490.4) & 41.6(17.5-98.1) \\ & & & \\ \text { CYP3A4*1G } & & & \\ \text { GG } & 72 & 205.4(33.8-547.6) & 42.4(6.8-118.3) \\ \text { AG } & 42 & 181.4(52.6-490.4) & 37.8(11.0-98.1) \\ \text { AA } & 12 & 170.7(84.5-288.5) & 34.6(16.9-61.5) \\ & & & \\ \text { CYP3A5*3C } & & & 34.6(16.9-51.3)^{b} \\ \text { AA } & 16 & 170.7(84.5-256.3)^{b} & 33.1(6.8-98.1)^{b} \\ \text { AG } & 46 & 160.5(33.8-490.4)^{b} & 34.3(9.7-118.3) \\ \text { GG } & 64 & 221.7(47.1-547.6) & 44.3\end{array}$

${ }^{\mathrm{b}} \mathrm{P}<0.05$ compared with GG (Nemenyi test for comparing three groups; Mann-Whitney $\mathrm{U}$ test for comparing two groups).

among the 4 CYP3A4-CYP3A5 haplotypes for further analysis because they were more frequent than AG and GA. Patients with the AA haplotype exhibited lower CsA pharmacokinetics than those with non-AA haplotypes $(P<0.05)$. GG haplotype patients did not differ from non-GG haplotype patients. Moreover, among the 11 ABCB1 1234-2677-3435 haplotypes, we selected the TTT, TGC, and CGC haplotypes for further analysis because they were more frequent than the 9 other haplotypes. None of them correlated with CsA pharmacokinetics (Table 5).

\section{Combined impact of genetic factors and clinical indices on CsA} pharmacokinetics

Because our analysis revealed that only CYP3A $5 * 3 \mathrm{C}$ correlated with CsA pharmacokinetics, we established a multiple regression model to assess the association between the SNP and CsA pharmacokinetics more efficiently by considering clinical factors. First, we individually examined age, sex, cold ischemia time, as well as hemoglobin, BUN, and BCr levels, against the log-transformed $C_{0} /$ dose using Pearson's correlation test to select candidate predictors for further multiple regression analysis. Age and hemoglobin, $\mathrm{BUN}$, and $\mathrm{BCr}$ levels were retained in the model $(P<0.05)$. CYP3A5*3C maintained a significant correlation with the log-transformed $C_{0} /$ dose and accounted for $44.2 \%$ of the stepwise regression model $\left(r^{2}=0.31\right)$ (Table 6).

Table 5. Associations between the CYP3A and ABCB1 haplotypes and CsA pharmacokinetics.

\begin{tabular}{lccc}
\hline & Number & $\begin{array}{c}\text { CsA } C_{0}(\mathrm{ng} / \mathrm{mL}) \\
\text { Median (Range) }\end{array}$ & $\begin{array}{c}\mathrm{C}_{0} / \text { dose } \\
(\mathrm{ng} / \mathrm{mL}, \text { per mg/kg) } \\
\text { Median (Range) }\end{array}$ \\
\hline ABCB1 1236-2677-3435 & & \\
TTT & 86 & $198.6(33.8-547.6)$ & $40.6(6.8-118.3)$ \\
non-TTT & 40 & $180.7(52.6-451.3)$ & $37.5(11.0-93.0)$ \\
TGC & 58 & $187.4(33.8-547.6)$ & $38.4(6.8-118.3)$ \\
non-TGC & 68 & $198.6(65.1-490.4)$ & $40.4(13.0-98.0)$ \\
CGC & 36 & $208.4(52.6-395.0)$ & $43.2(11.0-79.0)$ \\
non-CGC & 90 & $185.9(33.8-547.6)$ & $38.4(6.8-118.3)$ \\
CYP3A4-CYP3A5 & & & \\
GG & 109 & $200.9(33.8-547.6)$ & $41.3(6.8-118.3)$ \\
non-GG & 17 & $181.5(84.5-288.5)$ & $37.2(16.9-61.5)$ \\
AA & 40 & $155.1(82.2-490.4)^{b}$ & $31.6(16.9-98.1)^{b}$ \\
non-AA & 86 & $208.4(33.8-547.6)$ & $43.2(6.8-118.3)$ \\
\hline
\end{tabular}

${ }^{\mathrm{b}} \mathrm{P}<0.05$ compared with non-AA (Mann-Whitney U test).

Table 6. Multiple linear regression analyses of variables influencing the log-transformed $C_{0}$ /dose.

\begin{tabular}{lllll}
\hline $\begin{array}{l}\text { Dependent } \\
\text { variable }\end{array}$ & $\begin{array}{c}\text { Independent } \\
\text { variables }\end{array}$ & $\begin{array}{c}\text { Standardized } \\
\text { coefficients } \\
\text { beta }\end{array}$ & $t$ & Sig \\
\hline CsA/Dose & (Constant) & & 7.668 & $0.000^{\mathrm{b}}$ \\
log-transformed & & & & \\
& CYP3A5_D1 & -0.189 & -2.360 & $0.020^{\mathrm{b}}$ \\
& CYP3A5_D2 & -0.253 & -2.360 & $0.002^{\mathrm{b}}$ \\
& Hemoglobin & 0.285 & -3.171 & $0.000^{\mathrm{b}}$ \\
& BCr & -0.253 & -3.248 & $0.002^{\mathrm{b}}$ \\
& Age & 0.228 & 2.952 & $0.004^{\mathrm{b}}$ \\
\hline
\end{tabular}

CYP3A5_D1 represents a dummy variable defined as AG relative to the GG genotype for CYP3A5*3C, and CYP3A5_D2 represents a dummy variable defined as AA relative to the GG genotype for CYP3A5*3C. ${ }^{b} P<0.05$.

\section{Discussion}

In this study, we observed that neither the CYP3A4*1G, ABCB1 1236C $>$ T, ABCB1 2677G $>$ T/A, and ABCB1 3435C $>$ T alleles nor the CYP3A4-CYP3A5 GG, ABCB1 1236-2677-3435 TTT, CGC, and TGC haplotypes was associated with the CsA $C_{0}$ /dose in early renal transplant recipients. In contrast, carriers of the CYP3A5*3C allele and CYP3A AA haplotype exhibited a higher $\mathrm{CsA}_{0}$ / dose than CYP3A5* 1 allele and CYP3A4CYP3A5 non-AA haplotype carriers. We concluded that CYP3A $5 * 3 C$ allele carriers retained a high CsA $C_{0} /$ dose in the multiple linear regression model. 
Previous studies have shown that CYP3A4*1G allele frequency is characterized by extensive ethnic variation. This allele is infrequently observed in Caucasians but common in Asians. CYP3A4*1G is observed in approximately $25 \%-49 \%$ of Asian populations ${ }^{[19]}$, and our data confirmed this result (26.2\%). We investigated the role of CYP3A4*1G in CsA pharmacokinetics in early renal transplant recipients and revealed that the wild type and mutant patients did not differ in CsA pharmacokinetics, including in the $C_{0}$ and $C_{0} /$ dose. However, one study demonstrated that the CYP3A $4 * 1 \mathrm{G}$ allele correlated with the $\mathrm{CsA} \mathrm{C}_{0}$ during testing days $16-30^{[7]}$. We speculate that the selection of different time points for CsA pharmacokinetics could contribute to such disparate results.

Our findings also revealed that the CYP3A5*3C frequency was $69 \%$, similar to data from other studies in Chinese patients ${ }^{[20,21]}$, whereas the frequencies in Caucasian and African American populations have been reported as $85 \%$ and $45 \%$, respectively ${ }^{[22]}$. These results indicate that significant ethnic variations for the allele do exist. Although studies have consistently shown an association between CYP3A5*3C and the pharmacokinetics of tacrolimus, another $\mathrm{CNI}$, reports on the association between the SNP and CsA pharmacokinetics are contradictory. We compared several studies that analyzed CsA pharmacokinetics on the seventh day after renal transplantation in Chinese patients, and interestingly, we did not observe conflicting results. Thus, CsA pharmacokinetic time points and patient ethnicity affected the association between CYP3A5*3C and CsA pharmacokinetics. Furthermore, a metaanalysis suggested that CYP3A5*3 correlates with CsA pharmacokinetics in Asians ${ }^{[23]}$.

An LD has been observed between CYP3A4*1G and CYPE3A5*3C carriers in Asian populations ${ }^{[24]}$. Our data confirmed this correlation $\left(D^{\prime}=0.64\right)$ and revealed that GG and AA frequencies jointly accounted for $84 \%$ of CYP3A4CYP3A5 haplotypes. We then performed a CYP3A4-CYP3A5 haplotype analysis to assess their combined effect, which indicated that CsA pharmacokinetics were lower in patients with the AA haplotype than in patients with non-AA haplotypes $(P<0.05)$, thereby validating the effect of CYP3A5*3C on CsA pharmacokinetics. However, CsA pharmacokinetics did not differ between patients with the GG haplotype and patients with non-GG haplotypes. This result could be attributed to the low statistical power limited by the small sample size.

ABCB1 polymorphisms were distributed differently between ethnic groups. For example, ABCB1 2677 G>T/A is one of the most common and extensively reported SNPs. Previous research has shown that the A allele is observed in $13 \%$ of Chinese, $2 \%$ of Caucasians, and $0 \%$ of Africans ${ }^{[25-27]}$. We detected a rate of $14.3 \%$ in our Chinese patients, consistent with the above data for the Chinese population. In addition, a strong LD among ABCB1 1236, ABCB1 2677, and ABCB1 3435 has been observed in previous studies ${ }^{[28]}$. Our results showed that the TGC frequency accounted for $24.3 \%$ of ABCB1 12362677-3435 haplotypes, similar to the value of $20.5 \%$ reported by Qiu et $a l^{[7]}$. However, the frequency of this haplotype only accounted for $4.2 \%$ in Czech nationals ${ }^{[29]}$. Thus, our data con- firmed the diversity of ABCB1 mutations in several populations. We also assessed the impact of ABCB1 polymorphisms and their haplotypes on CsA pharmacokinetics in renal transplant patients, demonstrating that none of the three classic polymorphisms (1236 C>T, $2677 \mathrm{G}>\mathrm{T} / \mathrm{A}$, and $3435 \mathrm{C}>\mathrm{T})$ or the three main haplotypes (TTT, TGC, and CGC) were linked to CsA pharmacokinetics, in agreement with several studies ${ }^{[8,29]}$ but in contrast to others ${ }^{[6,7]}$. We postulate that the different experimental methods and conditions used in the present and previous studies could partly account for the conflicting results. Moreover, different studies on the associations between ABCB1 polymorphisms and CsA pharmacokinetics have selected different pharmacokinetic parameters: some used $C_{0}$, whereas others used $C_{2}$, which is the concentration at $2 \mathrm{~h}$ post-dose. $C_{2}$ has been proposed as more efficient than $C_{0}$ by some studies and not by others ${ }^{[30,31]}$. Therefore, identification of appropriate selection parameters requires further independent validation.

Finally, to elucidate the impact of CYP3A5*3C on CsA pharmacokinetics, we screened several variables correlated with the CsA $C_{0} /$ dose using Pearson's correlation test. For example, age was positively associated with the $C_{0} /$ dose, which might be due to CYP3A's decreasing ability to metabolize CsA with increased age ${ }^{[32]}$. However, the positive correlation of hemoglobin with $C_{0}$ /dose is likely a result of low hemoglobin values obtained from low hematocrit values, potentially resulting in a reduced proportion of CsA bound to red blood cells and an increased plasma portion more readily metabolized by the liver ${ }^{[21]}$. Moreover, specific indices for identifying DGF and AR in clinical practice, BUN and BCr were identified as negative correlates of the $C_{0}$ /dose. We speculated that their high values were attributable to the low CsA $C_{0}$, which readily led to DGF or AR. Therefore, we established a stepwise regression model to further observe the effects of CYP3A5*3C on CsA pharmacokinetics while considering clinical factors. We selected clinical variables, such as age and hemoglobin, BUN, and BCr levels, that, except BUN, were in the stepwise regression model. Bun was excluded possibly because it was influenced by many factors, such as food, drugs, and sports activities, yielding a diminished effect in the complicated multiple-factor environment. Our model demonstrated that CYP3A5*3C exhibited an independent, significant correlation with CsA pharmacokinetics and accounted for $44.2 \%$ of the model.

This study was not without limitations, partly reflected by the low $r^{2}$ value in the regression model. We speculate that other factors may affect CsA pharmacokinetics, including methylation, microRNA regulation, and the copy number variations of relevant genes ${ }^{[33]}$, as well as serum lipid profiles, hematocrit levels, and comorbidities (eg, diabetes and hypertension $)^{[3,18]}$. Concurrently, the medication prednisone was routinely used in renal transplant patients because of its efficacy in reducing AR. Thus, although studies have shown that the administration of this drug induced CYP3A ${ }^{[34]}$, we could not have excluded those patients who were taking prednisone. Moreover, we did not consider the genetic factors of donors 
because their organ samples did not remain intact, whereas several studies have demonstrated that the ABCB1 $3435 \mathrm{C}>\mathrm{T}$ genotype of donors correlated with CsA pharmacokinetics ${ }^{[35]}$.

In summary, our study assessed the impact of CYP3A $5 * 3 \mathrm{C}$ on CsA pharmacokinetics on the seventh day after renal transplantation in Chinese patients. This allele serves as a putative indicator for predicting the optimal CsA dose for early renal transplantation.

\section{Acknowledgements}

This work was supported by the National Natural Science Foundation of China (Nos 30801421, 30901834, 81001476, and 81072706), Program for Changjiang Scholars and Innovative Research Team in University (IRT0946), Scientific Foundation of Hunan (№s 11K073 and 10JJ4020), 863 Project (Nos 2009AA022710 and 2009AA022703), and NCET-10-0843.

\section{Author contribution}

Hong-hao ZHOU, Xiang-guang MENG, and Wei ZHANG designed the study; Xiang-guang MENG, Cheng-xian GUO, Xiang-dong PENG, Qi PEI conducted the research; Guo WANG, Meng HE, Min LIU, and Jing-ke YANG contributed new analytical tools and reagents; Xiang-guang Meng collected the medical records of the patients and analyzed the data; Jian-le HAN, Xin CHEN, Yong SHI, and Hong-yao SHI collected samples from the patients; and Xiang-guang MENG, Ji-ye YIN, Guo-qing FENG, Ying-chun ZHAO, and Bo-ting ZHOU wrote the manuscript.

\section{References}

1 Colombo D, Ammirati E. Cyclosporine in transplantation - a history of converging timelines. J Biol Regul Homeost Agents 2011; 25 : 493-504.

2 Masuda S, Inui K. An up-date review on individualized dosage adjustment of calcineurin inhibitors in organ transplant patients. Pharmacol Ther 2006; 112: 184-98.

3 Garcia-Saiz M, Lopez-Gil A, Alfonso I, Boada JN, Armijo JA. Factors influencing cyclosporine blood concentration-dose ratio. Ann Pharmacother 2002; 36: 193-9.

4 Roy JN, Lajoie J, Zijenah LS, Barama A, Poirier C, Ward BJ, et al. CYP3A5 genetic polymorphisms in different ethnic populations. Drug Metab Dispos 2005; 33: 884-7.

5 Kuehl P, Zhang J, Lin Y, Lamba J, Assem M, Schuetz J, et al. Sequence diversity in CYP3A promoters and characterization of the genetic basis of polymorphic CYP3A5 expression. Nat Genet 2001; 27: 383-91.

6 Hu YF, Qiu W, Liu ZQ, Zhu L, Tu JH, Wang D, et al. Effects of genetic polymorphisms of CYP3A4, CYP3A5 and MDR1 on cyclosporine pharmacokinetics after renal transplantation. Clin Exp Pharmacol Physiol 2006; 33: 1093-8.

7 Qiu XY, Jiao Z, Zhang M, Zhong $\sqcup$, Liang $\mathrm{HQ}$, Ma CL, et al. Association of MDR1, CYP3A4*18B, and CYP3A5*3 polymorphisms with cyclosporine pharmacokinetics in Chinese renal transplant recipients. Eur J Clin Pharmacol 2008; 64: 1069-84.

8 Bouamar R, Hesselink DA, van Schaik RH, Weimar W, Macphee IA, de Fijter JW, et al. Polymorphisms in CYP3A5, CYP3A4, and ABCB1 are not associated with cyclosporine pharmacokinetics nor with cyclosporine clinical end points after renal transplantation. Ther Drug Monit 2011; 33: 178-84.
9 Turolo S, Tirelli AS, Ferraresso M, Ghio L, Belingheri M, Groppali $\mathrm{E}$, et al. Frequencies and roles of CYP3A5, CYP3A4 and ABCB1 single nucleotide polymorphisms in Italian teenagers after kidney transplantation. Pharmacol Rep 2010; 62: 1159-69.

10 Shi XJ, Geng F, Jiao Z, Cui XY, Qiu XY, Zhong MK. Association of $A B C B 1, C Y P 3 A 4 * 18 B$ and CYP3A5*3 genotypes with the pharmacokinetics of tacrolimus in healthy Chinese subjects: a population pharmacokinetic analysis. J Clin Pharm Ther 2011; 36: 614-24.

11 Zeng Y, He YJ, He FY, Fan L, Zhou HH. Effect of bifendate on the pharmacokinetics of cyclosporine in relation to the CYP3A4*18B genotype in healthy subjects. Acta Pharmacol Sin 2009; 30: 478-84.

12 Qiu F, He XJ, Sun YX, Li-Ling J, Zhao LM. Influence of ABCB1, CYP3A $4 * 18 B$ and CYP3A5*3 polymorphisms on cyclosporine $A$ pharmacokinetics in bone marrow transplant recipients. Pharmacol Rep 2011; 63: 815-25.

13 Fukushima-Uesaka H, Saito Y, Watanabe H, Shiseki K, Saeki M, Nakamura T, et al. Haplotypes of CYP3A4 and their close linkage with CYP3A5 haplotypes in a Japanese population. Hum Mutat 2004; 23 : 100.

14 Haufroid V. Genetic polymorphisms of ATP-binding cassette transporters $\mathrm{ABCB} 1$ and $\mathrm{ABCC} 2$ and their impact on drug disposition. Curr Drug Targets 2011; 12: 631-46.

15 Santoro A, Felipe CR, Tedesco-Silva H, Medina-Pestana JO, Struchiner CJ, Ojopi EB, et al. Pharmacogenetics of calcineurin inhibitors in Brazilian renal transplant patients. Pharmacogenomics 2011; 12: 1293-303.

16 Azarpira N, Aghdaie MH, Behzad-Behbahanie A, Geramizadeh B, Behzadi S, Malekhoseinie SA, et al. Association between cyclosporine concentration and genetic polymorphisms of CYP3A5 and MDR1 during the early stage after renal transplantation. Exp Clin Transplant 2006; 4: 416-9.

17 Wang Y, Wang C, Li J, Wang X, Zhu G, Chen X, et al. Effect of genetic polymorphisms of CYP3A5 and MDR1 on cyclosporine concentration during the early stage after renal transplantation in Chinese patients co-treated with diltiazem. Eur J Clin Pharmacol 2009; 65: 239-47.

$18 \mathrm{Hu}$ RH, Lee PH, Tsai MK. Clinical influencing factors for daily dose, trough level, and relative clearance of tacrolimus in renal transplant recipients. Transplant Proc 2000; 32: 1689-92.

19 Staatz CE, Goodman LK, Tett SE. Effect of CYP3A and ABCB1 single nucleotide polymorphisms on the pharmacokinetics and pharmacodynamics of calcineurin inhibitors: Part I. Clin Pharmacokinet 2010; 49: 141-75.

20 Chu XM, Hao HP, Wang GJ, Guo LQ, Min PQ. Influence of CYP3A5 genetic polymorphism on cyclosporine A metabolism and elimination in Chinese renal transplant recipients. Acta Pharmacol Sin 2006; 27 : 1504-8.

21 Li L, Li CJ, Zheng L, Zhang YJ, Jiang HX, Si-Tu B, et al. Tacrolimus dosing in Chinese renal transplant recipients: a population-based pharmacogenetics study. Eur J Clin Pharmacol 2011; 67: 787-95.

22 Lamba JK, Lin YS, Schuetz EG, Thummel KE. Genetic contribution to variable human CYP3A-mediated metabolism. Adv Drug Deliv Rev 2002; 54: 1271-94.

23 Tang HL, Ma LL, Xie HG, Zhang T, Hu YF. Effects of the CYP3A5*3 variant on cyclosporine exposure and acute rejection rate in renal transplant patients: a meta-analysis. Pharmacogenet Genomics 2010; 20: 525-31.

24 Miura M, Satoh S, Kagaya H, Saito M, Numakura K, Tsuchiya N, et al. Impact of the CYP3A4*1G polymorphism and its combination with CYP3A5 genotypes on tacrolimus pharmacokinetics in renal transplant patients. Pharmacogenomics 2011; 12: 977-84. 
25 Cheung CY, Op den Buijsch RA, Wong KM, Chan HW, Chau KF, Li CS, et al. Influence of different allelic variants of the CYP3A and ABCB1 genes on the tacrolimus pharmacokinetic profile of Chinese renal transplant recipients. Pharmacogenomics 2006; 7: 563-74.

26 Cascorbi I, Gerloff T, Johne A, Meisel C, Hoffmeyer S, Schwab M, et al. Frequency of single nucleotide polymorphisms in the P-glycoprotein drug transporter MDR1 gene in white subjects. Clin Pharmacol Ther 2001; 69: 169-74.

27 Kim RB, Leake BF, Choo EF, Dresser GK, Kubba SV, Schwarz UI, et al. Identification of functionally variant MDR1 alleles among European Americans and African Americans. Clin Pharmacol Ther 2001; 70 : 189-99.

28 Kroetz DL, Pauli-Magnus C, Hodges LM, Huang CC, Kawamoto M, Johns SJ, et al. Sequence diversity and haplotype structure in the human ABCB1 (MDR1, multidrug resistance transporter) gene. Pharmacogenetics 2003; 13: 481-94.

29 Bandur S, Petrasek J, Hribova P, Novotna E, Brabcova I, Viklicky O. Haplotypic structure of ABCB1/MDR1 gene modifies the risk of the acute allograft rejection in renal transplant recipients. Transplantation 2008; 86: 1206-13.

30 Hermann M, Enseleit F, Fisler AE, Flammer A, Luscher TF, Noll G, et al. Cyclosporine C0-versus C2-monitoring over three years in maintenance heart transplantation. Swiss Med Wkly 2011; 141: w13149.

31 Knight SR, Morris PJ. The clinical benefits of cyclosporine C2-level monitoring: a systematic review. Transplantation 2007; 83: 1525-35.

32 Sommerer C, Schnitzler P, Meuer S, Zeier M, Giese T. Pharmacodynamic monitoring of cyclosporin A reveals risk of opportunistic infections and malignancies in renal transplant recipients 65 years and older. Ther Drug Monit 2011; 33: 694-8.

$33 \mathrm{Zhu} \mathrm{H}, \mathrm{Ge} \mathrm{W}$. Future of the pharmacogenomics of calcineurin inhibitors in renal transplant patients. Pharmacogenomics 2011; 12 : 1505-8.

34 El-Sankary W, Plant NJ, Gibson GG, Moore DJ. Regulation of the CYP3A4 gene by hydrocortisone and xenobiotics: role of the glucocorticoid and pregnane X receptors. Drug Metab Dispos 2000; 28: 493-6.

35 Woillard JB, Rerolle JP, Picard N, Rousseau A, Guillaudeau A, Munteanu E, et al. Donor P-gp polymorphisms strongly influence renal function and graft loss in a cohort of renal transplant recipients on cyclosporine therapy in a long-term follow-up. Clin Pharmacol Ther 2010; 88: 95-100. 